\title{
Mapping Paddy Field Extent and Temporal Pattern Variation in a Complex Terrain Area using Sentinel 1- Time Series Data: Case Study of Magelang District, Indonesia
}

\author{
Arjasakusuma, S., "' Kusuma, S. S., Mahendra, W. K. and Astriviany, N. \\ Department of Geographic Information Science, Faculty of Geography, Universitas Gadjah Mada, \\ Yogyakarta, Jl. Kaliurang, Sekip Utara, Bulaksumur Sinduadi Sleman, Senolowo, Sinduadi, Kec. Mlati, \\ Kabupaten Sleman, Daerah Istimewa Yogyakarta 5528, Indonesia \\ E-mail: sanjiwana.arjasakusuma@ugm.ac.id,*sandiaga.kusuma@mail.ugm.ac.id, \\ william.krista.mahendra@mail.ugm.ac.id \\ *Corresponding Author
}

\begin{abstract}
The availability of free Synthetic Aperture Radar (SAR) data of Sentinel 1A/B, with the high temporal resolution, has provoked the usage of time-series backscatter values from the SAR data for mapping paddy field extent and crop phenology. However, paddy field extent mapping over complex terrain areas is rarely conducted, and the effect of terrain shadows on the accuracy of paddy field classification has not been addressed yet. This study attempted to identify the effect of terrain shadows on the paddy field mapping accuracy using monthly median composites Sentinel S1A data in 2018 and to perform the effort to minimize the misclassification by incorporating dem-derived terrain ruggedness index (TRI) in the random forest classifier. Lastly, this research also aimed to identify the general variation of the time-series backscatter of VV-and-VH polarization in the paddy field by employing unsupervised K-means classification. Our study showed that terrain shadow contributed to the misclassification of the identified paddy field due to the similar low backscatter values to the paddy field. Incorporating TRI can eliminate the misclassified paddy field, which subsequently increased the accuracy of paddy field mapping by $8-9 \%$ (user accuracy) and $4-5 \%$ (producer accuracy). In addition, means of clustered classes from unsupervised classification over paddy field areas generated temporal patterns related to the cropping frequencies and agreement with the weather pattern of the study area. This indicated that the cropping phase of paddy could be identified using the temporal pattern from 12-month median composites of the radar backscatter.
\end{abstract}

\section{Introduction}

Rice is the main staple food for many countries in Asia, particularly Indonesia. Indonesia is the country with the 3rd largest rice production in the world and is also the country with the largest rice consumption (Faostat, 2014). Like many other countries, paddy field in Indonesia is currently under pressure from land-use changes, which jeopardizes the future stocks of rice for fulfilling the growing population rice consumption. To be able to measure the current and future capacity of rice production from paddy field, rapid and accurate monitoring of paddy field extent and phenology related to the cropping intensity is essential.

Remote sensing has been employed for rapid mapping and monitoring paddy fields over large areas. For example, several studies used vegetation index data from optical remote sensing data such as SPOT Vegetation and MODIS time-series data in 1- $\mathrm{km}$ and 250-spatial resolution (Setiawan et al., 2014 and Xiao et al., 2002 and 2006). Xiao et al., (2006) tried to map paddy fields using a combination of the water index and vegetation index in deriving information of the rice planting phases. Setiawan et al., (2014) used the supervised classification by using temporal data from the vegetation index to map the frequencies of rice planting.

Vegetation indices from optical data have been widely used for identifying paddy field dynamics (Boschetti et al., 2009, Guan et al., 2016, Gumma et al., 2011, Peng et al., 2011 and Xiao et al., 2000 and 2006). However, the study of Xiao et al., (2006) reported the possibility of cloud interference that affected the accuracy of the classification results, while Setiawan et al., (2014) showed that the spatial resolution of $250 \mathrm{~m}$ from MODIS contains mixed pixel information, which contaminated the pixel 
values of paddy field. Thus, monitoring paddy field extent and the dynamics by using remote sensing data is now shifting into using cloud-free and higher spatial resolution data.

Sentinel-1 SAR data provides cloud-free and higher spatial resolution data $( \pm 10 \mathrm{~m}$ spatial resolution) every six days since 2014 by employing the constellation system of Sentinel $1 \mathrm{~A} / \mathrm{B}$ orbits. Such Sentinel-1 data characteristics are beneficial to be used mainly in tropical areas where persistent clouds exist. Several studies such as Guan et al., (2016) has implemented time-series sentinel data for mapping paddy field extent and dynamics in Northern of West Java, Indonesia, Lasko et al., (2018) used time-series data to map the cropping intensity in Vietnam and found that both polarization is useful to generate the accurate mapping of paddy field, and Onojeghuo et al., (2018) and Torbick et al., (2016) which used the combination of Sentinel-1 and Landsat 8 plus Sentinel 2 for paddy field's cropping patterns in China and Myanmar. Clauss et al., (2018) stated that different planting stages in the paddy field generated a distinct temporal pattern due to the different backscatter - surface interaction during different covers at different planting stages, so that

(A)
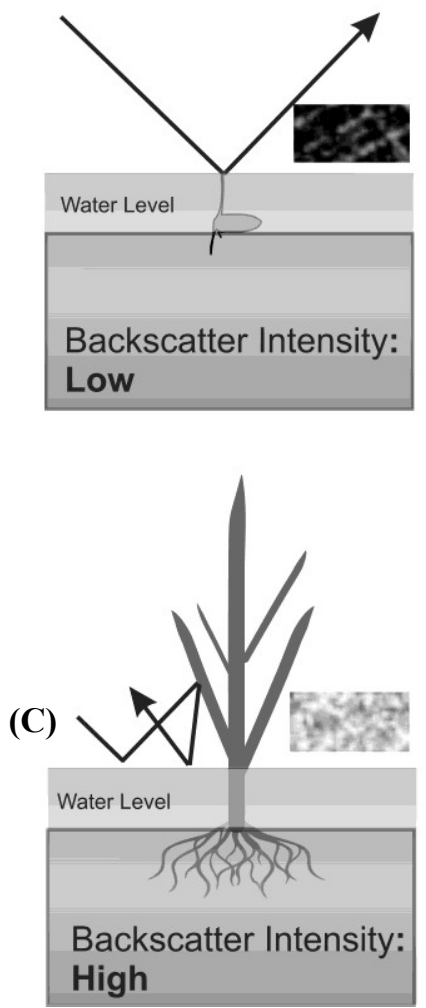

mapping using time-series Sentinel 1 data is useful for identifying paddy field. The previous studies have demonstrated the ability of Sentinel-1 time series data for paddy field mapping and monitoring. However, the role of terrain effect on paddy field classification accuracy has not yet been discussed.

All SAR data are susceptible to the terrain shadows problem, which appears on the terrain areas opposite to the microwave beams' incidence angle. The lower values in the shadow areas could render similar pixel values to the paddy field during the flooding and harvesting phase, which appear darker at this stage (Figure 1 from Clauss et al., (2018)). These similarities may hamper the identification of paddy fields from time-series backscatter data due to the flooding stage and harvesting stage are identified as the essential variables for mapping paddy fields using machine learning (Lasko et al., 2018) which can cause a misclassification due to similar backscatter values with shadow areas. Therefore, it is crucial to assess Sentinel time-series data's performance to map and monitor paddy fields over a complex terrain area where terrain shadows are ubiquitous.
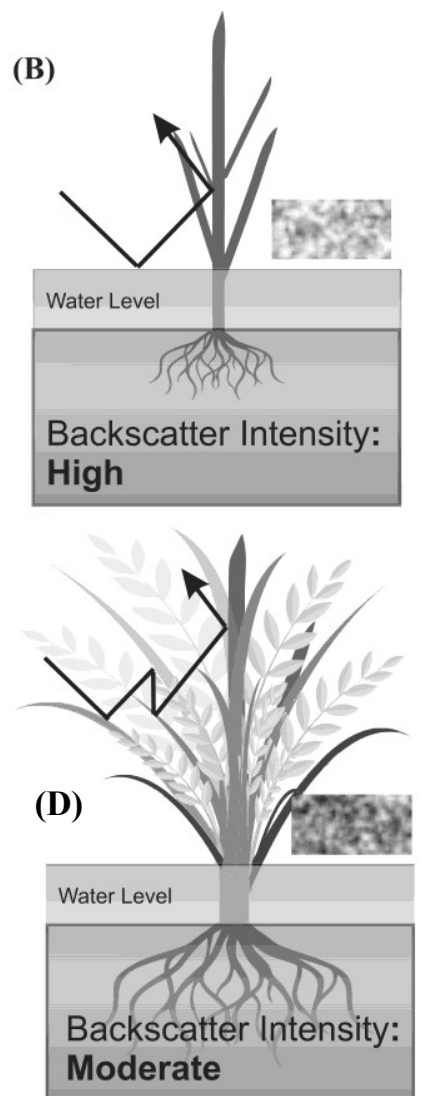

Figure 1: Radar backscatter mechanisms during different growth stages of paddy and example of the resulted backscatter intensities in C-band sentinel-1 data (A to D) (adapted from Clauss et al., 2018)

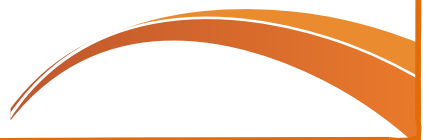


Therefore, this research aims to assess Sentinel dualpolarization data's accuracy ( $\mathrm{VV}$ and $\mathrm{VH}$ ) for mapping paddy field extent and to understand the general temporal pattern of Sentinel-1 over paddy area. DEM-derived variable such as Terrain Ruggedness Index (TRI) was incorporated to understand this variable's role when used as the input for classifying paddy field over complex terrain areas.

\section{Study Area}

The study was conducted in the area of Magelang Regency, Central Java Province. The Magelang Regency is generally a highland in the form of a 'basin' surrounded by mountains (Merapi, Merbabu, Andong, Telomoyo, Sumbing) and Menoreh mountain. The Magelang Regency topography consists of 8.599 Ha of Plain Areas, 44.784 Ha of surging areas, $41.037 \mathrm{Ha}$ of steep areas $14.155 \mathrm{Ha}$ of very steep areas (http://www.magelangkab.go.id). The data used in this study were cropped based on the extent of the Magelang districts. The study areas' extent is from $110.044^{\circ}-110.4^{\circ} \mathrm{E}$ and $7.35^{\circ}-7.7^{\circ}$ S. The total area for our study is $122.469,4 \mathrm{Ha}$ (Figure 2).

\section{Methods}

\subsection{SAR Sentinel 1A}

The Sentinel 1A data (ascending orbit and relative orbit number is 25) was downloaded from Alaska Satellite Facility (ASF) https://www.asf.alaska.edu/ GRDH format. The data contained dual-polarization consisted of Vertical-Vertical (VV) and VerticalHorizontal (VH). There were 28 scenes of ascending Sentinel 1 data in 2018, which underwent a preprocessing routine suggested by Filipponi (2019). The preprocessing method covered the following steps: applying orbit file, thermal and border noise removal, calibration to sigma-nought, speckle filtering using modified lee with $5 \times 5$ window size range-doppler terrain correction, and cropping to the extent of the study area. Also, monthly mediancomposites were performed to generate monthly VVand-VH backscatter values in 2018 to reduce the noise and data size. Median values were chosen to avoid outliers that affect the values if average/mean composites were applied. The preprocessing steps resulted in a monthly $10-\mathrm{m}$ pixel size of dualpolarization Sentinel 1A dataset.

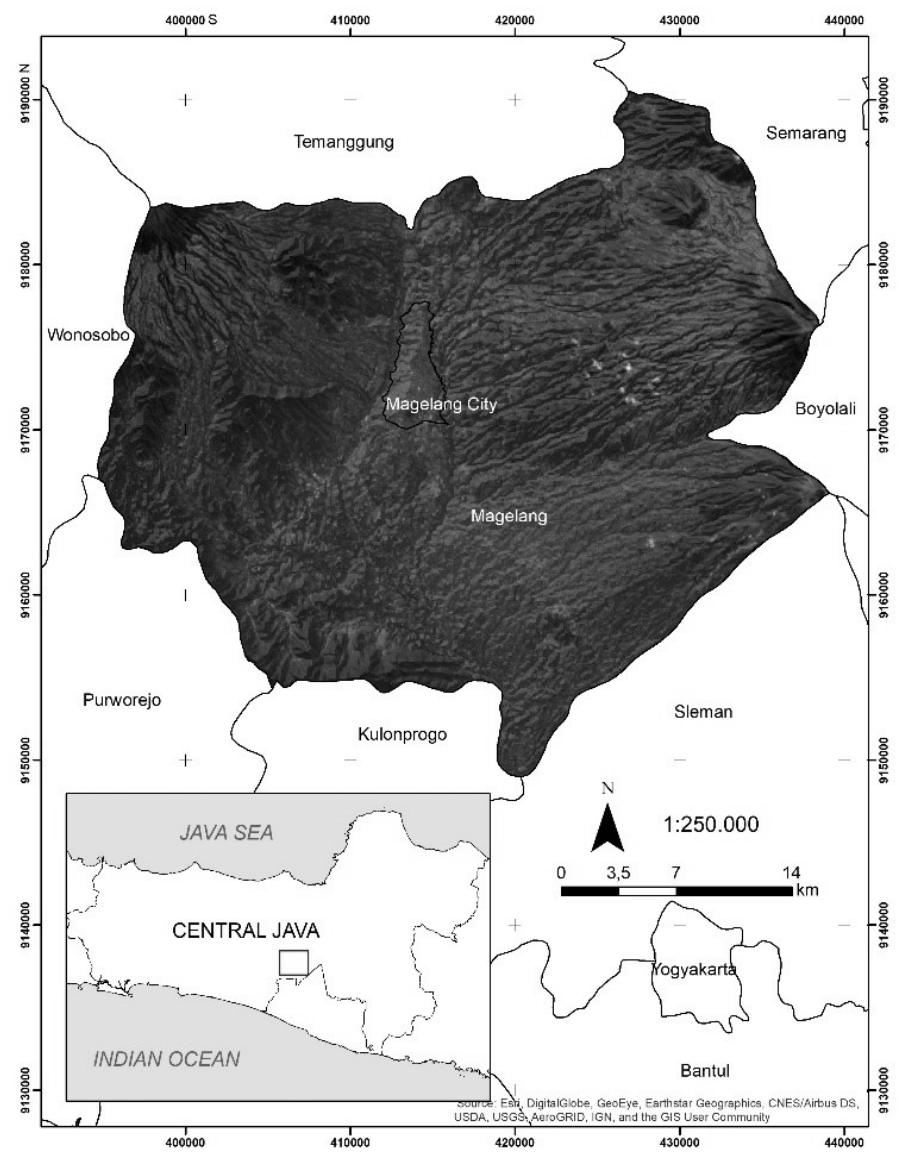

Figure 2: Study area map in Magelang district with terrain configuration represented by hillshades image in the background

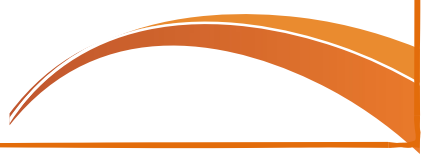




\section{Terrain Ruggedness Index (TRI)}

Terrain Ruggedness Index is an index developed by Riley et al., (1999) that indicates the surface roughness by looking at the mean height difference of one pixel from the 8 (eight) surrounding pixels. TRI data was derived from Digital Elevation Model (DEM) provided by the Indonesian Geospatial Agency (http://tides.big.go.id/DEMNAS/) in $8.1 \mathrm{~m}$ pixel resolution. The data were processed by using the TRI module in QGIS and resampled (bilinear) to follow the pixel size of the Sentinel 1A data so that it can be integrated into the Sentinel $1 \mathrm{~A}$ dataset. Bilinear resampling was chosen due to the continuous values presented in TRI and SAR Sentinel 1 data. It also gave better accuracy compared to the cubic convolution resampling method (Logan, 1979).

\subsection{Classification of Paddy Field Extent}

The classification process was performed by using the Random Forest algorithm, using the combination of variables from Sentinel 1A VV-and-VH data and TRI data. Random forest was chosen due to higher accuracy when used for paddy field mapping than the Support Vector Machine (Onojeghuo et al., 2018). Random forest is a bagging ensemble method, developed by Breiman (2001), which generated a random tree-based classification from the subset of the input data, and determined the classification result based on the majority vote (for classification) or average values (for regression). This classification works by using the number of trees and features used on the tree-classifier as the parameters, which were less than the support vector machine (Pal, 2005). The combination of different input variables in the classification process was conducted to assess the accuracy of VV-and-VH time-series data and the role of TRI data when being integrated as the input for classifying the paddy field.

Therefore, there are five combinations of variables in the classification process, such as:
1. VV-monthly data (12 layers)
2. VV- monthly + TRI data (13 layers)
3. VH-monthly data (12 layers)
4. VH-monthly + TRI data (13 layers)
5. VV-and-VH time-series + TRI data $(25$ layers)

Training samples were collected by using visual observation from the time-series sentinel data and google earth. The training samples over shadowed areas were also taken to ensure that the shadowed areas were represented in the training datasets. There are around 80 polygons of paddy-field and nonpaddy field training samples collected and used as the input data for training the algorithm with 5-fold iterations cross-validation. The classification was conducted in QGIS 3.8 by using Dzetsaka: classification tools developed by Karasiak (2017), and a majority filter with a $5 \times 5$ window size was used to simplify the classification result.

The paddy and non-paddy field maps resulted from this step were validated by using the point data collected by using the high-spatial-resolution data available from Google Earth (Pro). The sample points were randomly distributed by looking at the terrain configuration from TRI data to ensure proper distribution of point samples across the rough terrain. In addition, validation points that were overlapped or closely placed near the training area were removed. In total, 881 points were used to construct the confusion matrix to conduct the accuracy assessment and conclude the best classification inputs for paddy extent mapping by using Sentinel 1 time-series data. User accuracy (Ua), Producer accuracy (Pa), overall accuracy $(\mathrm{Oa})$, and kappa coefficient were calculated from the confusion matrix. 1 (one) training (and validation) dataset was collected, assuming that only a few land-use changes from paddy field to nonpaddy field occurred within one year.

\subsection{Identifying Temporal Pattern of Paddy Field}

The paddy field map with the highest accuracy from the classification process was used as the mask for separating paddy-field and non-paddy field from the input data. The masked data that corresponded to the paddy-field was classified using the unsupervised KMeans algorithm classification to group the backscatter temporal variation of the paddy-field pixels. In this unsupervised classification, the cluster was set to generate eight classes, and the iteration was set to 500 times. The monthly mean values from each group of clustered pixels were then used to generate the 12-months backscatter graph. The workflow of the study can be seen in Figure 3.

\section{Results}

\subsection{Paddy Field Classification Results}

There are five maps of paddy field extent resulted from the random forest classification (Figure 4). Table 1 summarized area distribution of the classified paddy fields in total, over rough and plain terrain areas, which was detected from the TRI data. Table 1 also showed the effect of terrain on the paddy field classification. 


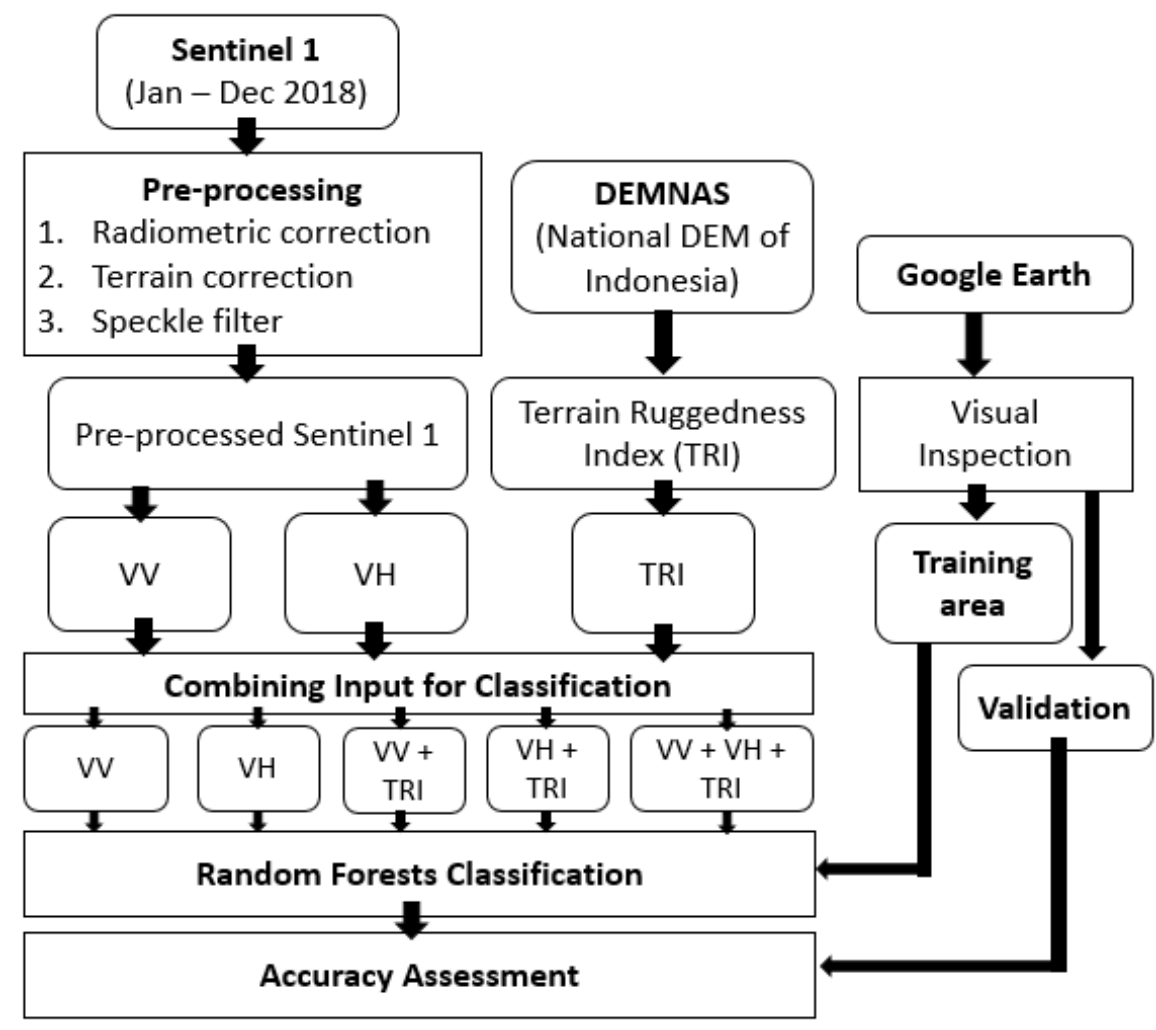

Figure 3: Workflow of this study

Table 1: Area of classified paddy fields from different data combination and their distribution across plain and rough terrain

\begin{tabular}{|c|c|c|c|c|c|c|c|}
\hline \multirow{2}{*}{ No } & \multirow{2}{*}{ Data } & \multicolumn{2}{|c|}{ Paddy Field (terrain) } & \multicolumn{2}{|c|}{ Paddy Field (plain) } & \multicolumn{2}{|c|}{ Paddy Field (all) } \\
\hline & & Area (ha) & $\%$ & Area (ha) & $\%$ & Area (ha) & $\%$ \\
\hline 1 & VH & $7,290.01$ & 13.30 & $20,531.42$ & 29.90 & $27,821.44$ & 14.94 \\
\hline 2 & VV & $12,379.30$ & 22.58 & $25,484.37$ & 37.11 & $37,863.67$ & 20.33 \\
\hline 3 & $\mathrm{VH}+\mathrm{TRI}$ & 808.14 & 1.03 & $34,739.18$ & 35.26 & $35,547.32$ & 13.31 \\
\hline 4 & $\mathrm{VV}+\mathrm{TRI}$ & 828.37 & 1.05 & $42,589.94$ & 43.23 & $43,418.30$ & 16.25 \\
\hline 5 & VH-VV + TRI & 977.43 & 1.24 & $39,796.02$ & 40.40 & $40,773.44$ & 15.26 \\
\hline
\end{tabular}

VV and VH classification without TRI as additional input data predicted the significant number of paddy field areas (12,379.3 ha and 7,290.01 ha) over terrain areas. These terrain-classified paddy field areas were then reduced when TRI data was introduced to the classification process, where only less than 1,000 ha of paddy fields were detected over the rough terrain areas. However, accuracy assessment should be conducted to understand if the reduction of paddy field areas over rough terrain configuration increases the final maps' accuracy.

\subsection{Accuracy of the Paddy Field Maps}

The classification of paddy field maps by employing time-series values from Sentinel 1 data resulted in overall accuracy above $>85 \%$ with an overall high user and producer accuracy for paddy field class (Table 2). Kappa coefficients for five maps are in minimum 0.77 and maximum 0.94 , suggesting that there are in minimum 77 to $94 \%$ possibility that the map agreements are happened not by chance. The highest accuracy was produced using the combination of $\mathrm{VV}, \mathrm{VH}$, and TRI data as the input variables with $96.94 \%$ overall accuracy (kappa: 0.94 ) with 93.2 and $100 \%$ of $\mathrm{Ua}$ and $\mathrm{Pa}$, correspondingly. In general, TRI data inclusion into the classification increased the classification performance, which can be seen in the higher values of the accuracy components (Ua, $\mathrm{Pa}, \mathrm{Oa}$, and kappa) when TRI data was used. 

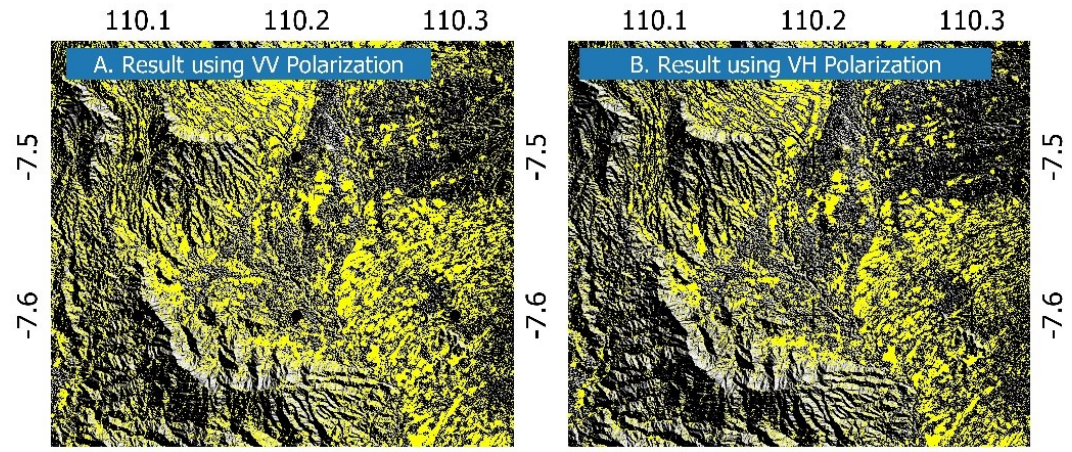

110.1

110.2

110.3

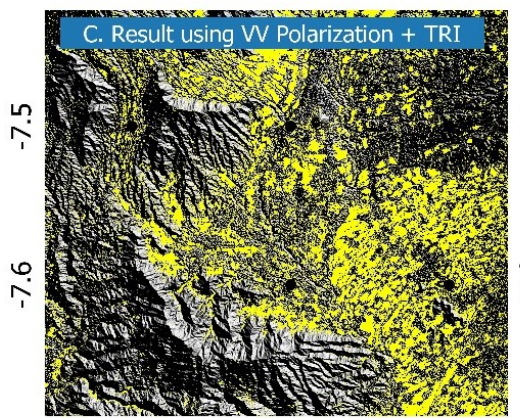

$$
110.1
$$

110.2

110.3

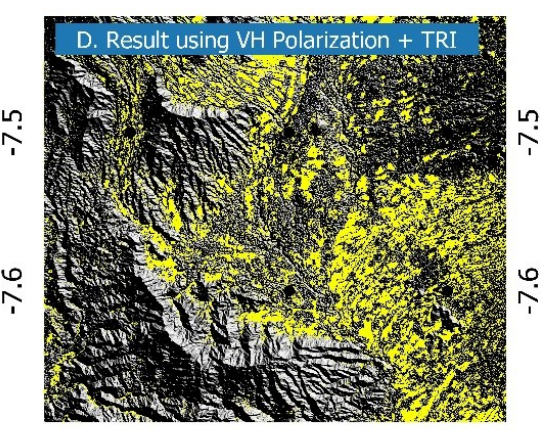

$$
110.1
$$

110.2

110.3

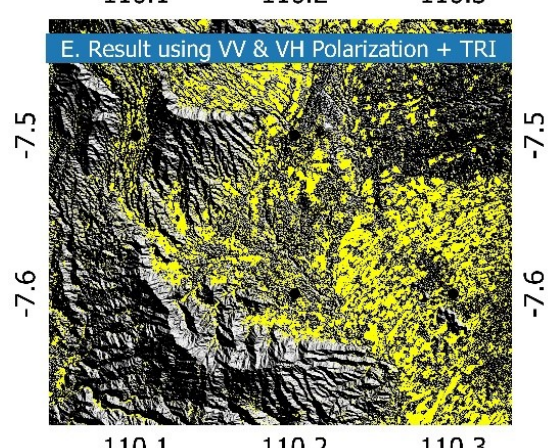

Paddy field extent using different classification inputs

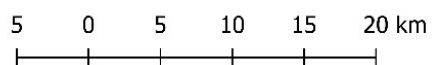

Legend

L Paddy Fields

Background hillshade

110.1

110.2

110.3

Figure 4: The identified paddy fields from random forest classification by using a different combination of Sentinel 1 polarization and TRI data

Table 2: Summary of accuracy assessment for paddy field classification

\begin{tabular}{|r|l|r|r|r|r|}
\hline \multirow{2}{*}{ No } & \multirow{2}{*}{ Data } & \multicolumn{4}{|c|}{ Accuracy Components } \\
\cline { 3 - 6 } & & \multicolumn{1}{c|}{ Ua } & \multicolumn{1}{c|}{ Pa } & \multicolumn{1}{l|}{ Oa } & \multicolumn{1}{c|}{ Kappa } \\
\hline 1 & VH & 83.37 & 90.81 & 88.54 & 0.77 \\
\hline 2 & VV & 81.35 & 94.32 & 88.54 & 0.77 \\
\hline 3 & VH + TRI & 91.67 & 95.14 & 94.32 & 0.88 \\
\hline 4 & VV + TRI & 90.32 & 98.38 & 94.89 & 0.90 \\
\hline 5 & VH-VV + TRI & 93.20 & 100.00 & $\mathbf{9 6 . 9 4}$ & $\mathbf{0 . 9 4}$ \\
\hline
\end{tabular}

When TRI data was not incorporated into the classification process, $\mathrm{VH}$ and VV gave an almost similar accuracy level. VH polarization gave slightly better user accuracy, whereas VV gave better producer accuracy. The paddy field map results with the best accuracy were used to mask the non-paddy field out of the image. The unsupervised classification can calculate VH and VV values' variation within a year by looking at the multitemporal values. Based on the summary provided in Table 2, the class of paddy field identified by using VH, VV, and TRI was used for the subsequent analysis. 
4.3 Temporal Variation in the Paddy Field Areas A Paddy field map with the highest accuracy was used to mask the VV-and-VH Sentinel 1 data to separate the paddy field from the non-paddy field. Kmean unsupervised classification was then used to identify VV and VH backscatter values' main patterns in 12 months. In the K-means algorithm, 8 clusters were set to be identified; however, the overly small clusters with only a few pixels were removed. In the end, there were 5 and 8 clusters of paddy fields were retained, and temporal patterns from each cluster were extracted by averaging the value from each month (Figure 5). VH and VV backscatter's general pattern showed relatively high values in the early months at the beginning of the year (January) until May and low values at July to September. In November, the backscatter values began to increase again. The pattern showed the relative coherence with the rainy and dry season when in 2018, the rainy season started in October (BMKG, 2017 and 2018).
This suggested that paddy field planting patterns in the study areas followed the weather pattern and the rainfall intensity.

\section{Discussion}

\subsection{Shadow and Accuracy Assessment Results}

The accuracy of paddy field extent mapping over complex terrain areas in this study has benefited from the inclusion of TRI variables which generated the best accurate map of paddy field extents. The increase of accuracy by incorporating DEM variables into the input for classification is similar to another study by Saha et al., (2005) which tried to classify land cover over rugged areas of Himalaya. The increase of accuracy also highlighted the role of shadow in affecting the paddy field classification. In the classification without using TRI, darker areas due to shadow were detected as paddy fields due to the similar tone with the flooded and post-harvested stage in paddy field areas.

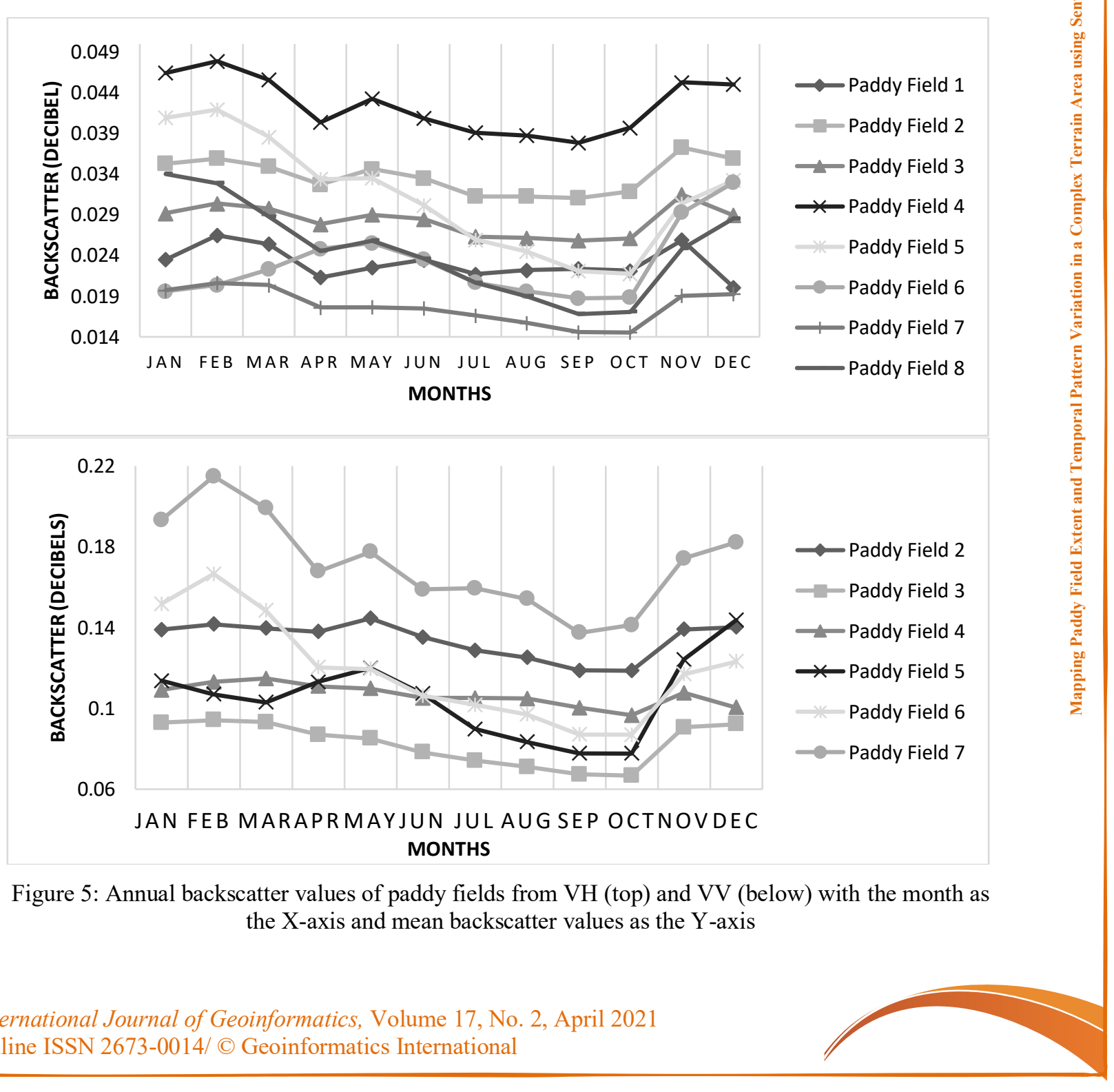


It is also worth noting that the increase of accuracy with the inclusion of DEM-derived variables is not limited to TRI usage. The slope variable, for instance, possesses similar information with TRI data and can be employed when the calculation of TRI data is not

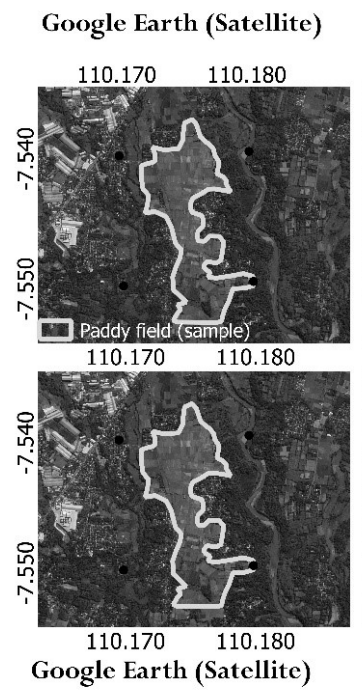

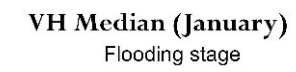
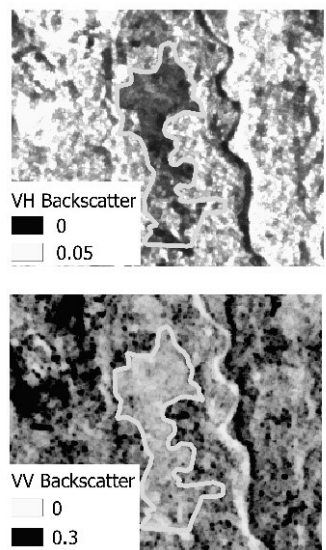

Google Earth (Satellite) possible or only slope data is available. Besides employing DEM-derived variables, another option for tackling the problem of shadow when classifying over complex terrain areas can be performed by combining the ascending and descending data.
VH Median (March)
Planting stage
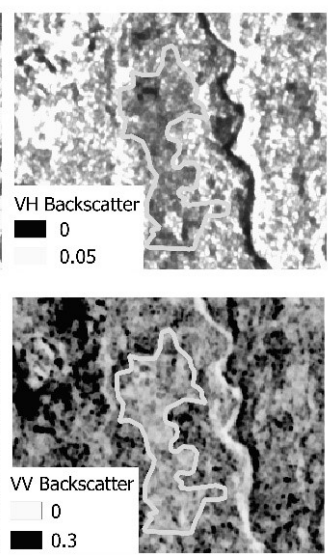

VV Median (March)
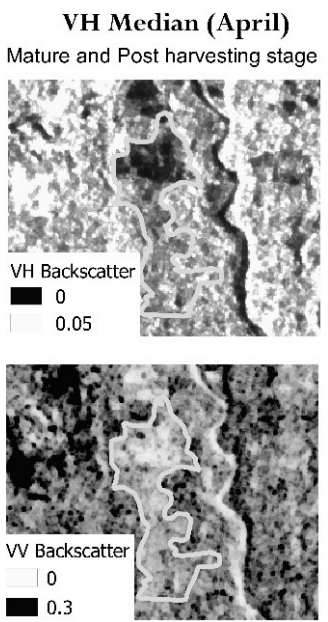

VV Median (April)

Figure 6: The multi-temporal SAR appearance of paddy field during different planting stage

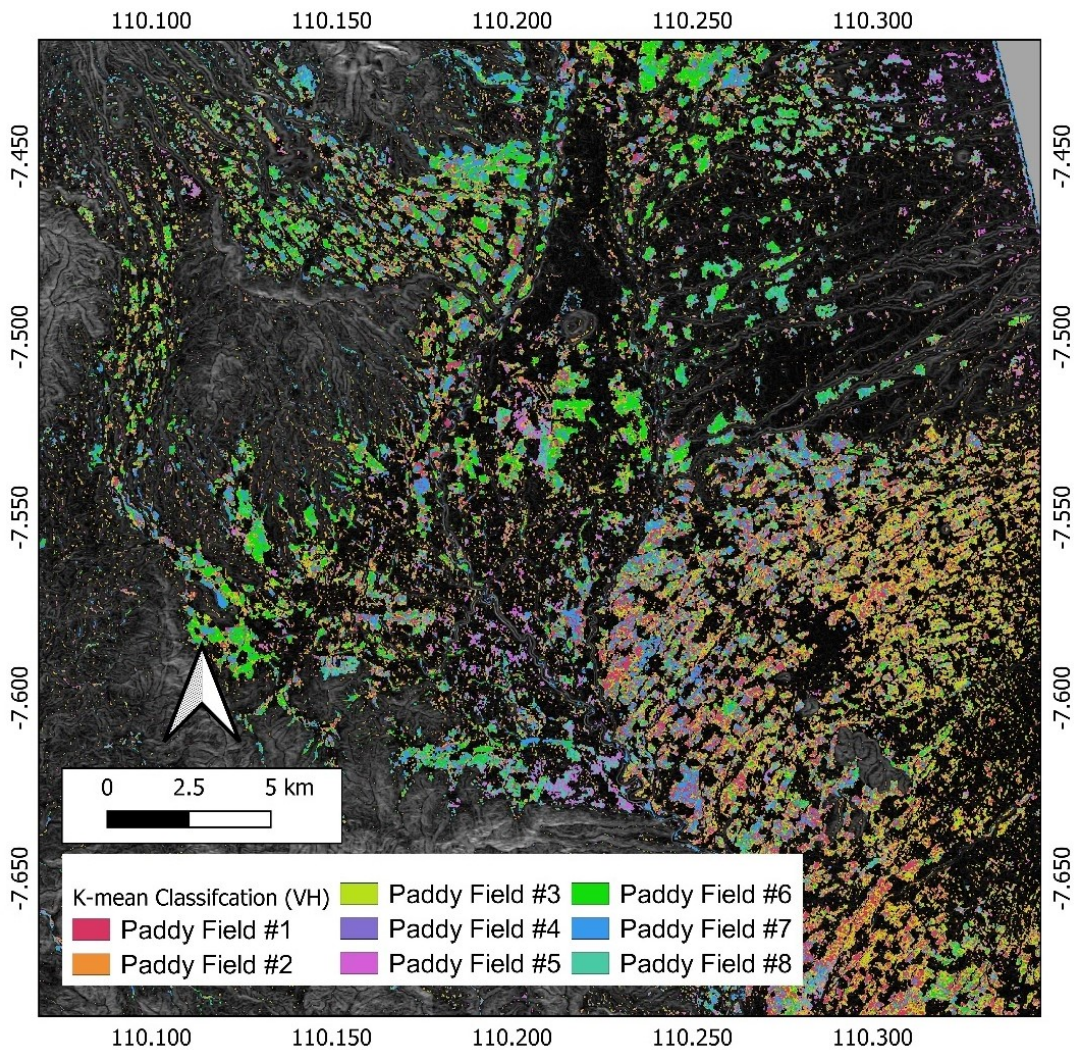

Figure 7: Example of K-means unsupervised results from $\mathrm{VH}$ polarization which clustered the similar type of phenology from paddy fields based on their temporal patterns, which indicated the diversities of the SAR temporal backscatter values on 2018 
Different incidence angles that those data possessed could give a multi-look angle direction that uncovers the data in the area covered by shadow in another orbit. Using ascending and descending data would increase the temporal resolution due to the increased revisit time. With the increased revisit time, a more detailed temporal pattern of paddy growth can be seen from the data. However, using ascending and descending data at the same time will increase the data volume, hence longer processing time.

The best map with the highest classification resulted from the classification by using the combination of $\mathrm{VV}, \mathrm{VH}$, and TRI data with more layers of data (25 layers of data) than other classification schemes. Higher classification using this dataset may result from the usage of random forest classifiers in this study, which worked best for high dimensionality data (Belgiu and Drăguț, 2016). Different classification algorithms may give different accuracy results from this study. Therefore, it drives a comparison study of classifying paddy fields from time-series Sentinel 1 data using different machine learning algorithms.

\subsection{Temporal Pattern of Paddy Fields}

The temporal pattern of VH-and-VV backscatter in a year showed a relatively similar pattern, although the values' magnitude is different (Figure 6). VVbackscatter over paddy field is higher when compared to the VH values. Furthermore, some temporal patterns of the backscatter values describe the cropping phenology. For instance, paddy field \#1 in VH-backscatter showed a possible double planting frequency/year with peaks in February, March, and April (rainy season). The backscatter's temporal pattern in paddy field areas followed the pattern of rainfall as low values in $\mathrm{VV}$-and-VH appeared during dry-season. In the future, an exploratory study employing the temporal signatures of the paddy field from Sentinel-1 can be conducted to be able to detect the paddy field areas and their cropping frequencies automatically.

The spatial distribution of the clusters from Kmeans classification also showed that paddy fields located close to each other tend to be grouped at the same class (example of clusters of paddy field in Figure 7). This indicates that the planting pattern in the paddy field could be driven by the terrain configuration, which determines the water availability that supplies the paddy fields which consequently, defines planting for a group of paddy fields.

\section{Conclusion}

Our study demonstrated the capability of time-series dual-polarization Sentinel 1 SAR data for paddy field extent mapping with a high accuracy level. However, this study also revealed the effect of terrain shadow in the SAR data, which reduced the classification accuracy. Incorporating terrain variables as an additional input for classification could eliminate the false-positive paddy field over shadowed areas. Our analysis of the temporal patterns of paddy fields generated from the VH and VV backscatter can be used to derive the general phenology of rice planting phases corresponded to the general weather patterns in the study area. The identified temporal pattern in the paddy field can be utilized for mapping the paddy field's planting stages and cropping intensities. Therefore, the future study can be addressed for exploring the possibility to map the paddy field extents and/or cropping frequency by generating empiric paddy field temporal signatures from radar data. Our study has not employed the full potential of Sentinel 1 data, such as the usage of the complete time-series data and combination of descending and ascending orbit, which could be beneficial to give a more detailed description of the paddy phenology. In addition, different incidence angles in descending orbit data may help solve the problem of shadow when performing classification.

\section{Acknowledgment}

This study was supported by Lecturer Research Grant no. 2056.45/UN1/FGE/KPT/SETD/2019 from the Faculty of Geography, Universitas Gadjah Mada, Yogyakarta, Indonesia.

\section{References}

Belgiu, M. and Drăguţ, L., 2016, Random Forest in Remote Sensing: A Review of Applications and Future Directions. ISPRS Journal of Photogrammetry and Remote Sensing, Vol. 114, 24-31.

BMKG, 2017, Prakiraan Musim Hujan 2017/2018 (Rainy season prediction in 2017/2018), in Geofisika, B. M. d., ed.: Indonesia.

BMKG, 2018, Prakiraan Musim Hujan 2018/2019 (Rainy season prediction in 2018/2019), in Geofisika, B. M. d., ed.: Indonesia.

Boschetti, M., Stroppiana, D., Brivio, P. and Bocchi, S., 2009, Multi-year Monitoring of Rice Crop Phenology through Time Series Analysis of MODIS images. International Journal of Remote Sensing, Vol. 30, 18, 4643-4662.

Breiman, L., 2001, Random Forests, Vol. 45, No. 1, 5-32. 
lauss, K., Ottinger, M. and Kuenzer, C., 2018, Mapping Rice Areas with Sentinel-1 Time Series and Superpixel Segmentation. International Journal of Remote Sensing, Vol. 39(5), 13991420.

Faostat, F., 2014, Food and Agriculture Organization Statistical Database: Retrieved Feb.

Filipponi, F., 2019, Sentinel-1 GRD Preprocessing Workflow. Proceedings Multidisciplinary Digital Publishing Institute Proceedings, Vol. 18, 11.

Guan, X., Huang, C., Liu, G., Meng, X. and Liu, Q., 2016, Mapping Rice Cropping Systems in Vietnam Using an NDVI-based Time-Series Similarity Measurement Based on DTW Distance. Remote Sensing, Vol. 8, No. 1, 19.

Gumma, M. K., Nelson, A., Thenkabail, P. S. and Singh, A. N., 2011, Mapping Rice Areas of South Asia Using MODIS Multitemporal Data. Journal of Applied Remote Sensing, Vol. 5, No. 1, 053547.

Karasiak, N., 2017, dzetsaka: Classification Tool.

Lasko, K., Vadrevu, K. P., Tran, V. T. and Justice, C., 2018, Mapping Double and Single Crop Paddy Rice with Sentinel-1A at Varying Spatial Scales and Polarizations in Hanoi, Vietnam. IEEE Journal of Selected Topics in Applied Earth Observations and Remote Sensing, Vol. 11(2), 498-512.

Logan, T. L., 1979, The Error Associated with Density Number (DN) Resampling of Landsat Forest Imagery for Multidate Registration. Proceedings Symposium on Machine Processing of Remotely Sensed Data June 27 - 29.

Onojeghuo, A. O., Blackburn, G. A., Wang, Q., Atkinson, P. M., Kindred, D. and Miao, Y., 2018, Mapping Paddy Rice Fields by Applying Machine Learning Algorithms to Multi-Temporal Sentinel-1A and Landsat data. International Journal of Remote Sensing, Vol. 39(4), 10421067.

Pal, M., 2005, Random Forest Classifier for Remote Sensing Classification. International Journal of Remote Sensing, Vol. 26(1), 217-222.
Peng, D., Huete, A. R., Huang, J., Wang, F. and Sun, H., 2011, Detection and Estimation of Mixed Paddy Rice Cropping Patterns with MODIS Data. International Journal of Applied Earth Observation and Geoinformation, Vol. 13(1), 1323.

Riley, S. J., DeGloria, S. D. and Elliot, R., 1999, Index that Quantifies Topographic Heterogeneity. Intermountain Journal of Sciences, Vol. 5(1-4), 23-27.

Saha, A., Arora, M., Csaplovics, E. and Gupta, R., 2005, Land Cover Classification Using IRS LISS III Image and DEM in a Rugged Terrain: A Case Study in Himalayas. Geocarto International, Vol. 20(2), 33-40.

Setiawan, Y., Rustiadi, E., Yoshino, K. and Effendi, H., 2014, Assessing the Seasonal Dynamics of the Java's Paddy Field Using MODIS Satellite Images. ISPRS International Journal of GeoInformation, Vol. 3(1), 110-129.

Torbick, N., Ledoux, L., Salas, W. and Zhao, M., 2016, Regional Mapping of Plantation Extent Using Multisensor Imagery. Remote Sensing, Vol. 8(3), 1-21.

Xiao, X., Boles, S., Frolking, S., Salas, W., Moore Iii, B., Li, C., He, L. and Zhao, R., 2002, Observation of Flooding and Rice Transplanting of Paddy Rice Fields at the Site to Landscape Scales in China Using VEGETATION Sensor Data. International Journal of Remote Sensing, Vol. 23(15), 3009-3022.

Xiao, X., Boles, S., Liu, J., Zhuang, D., Frolking, S., Li, C., Salas, W. and Moore III, B., 2005, Mapping Paddy Rice Agriculture in Southern China Using Multi-Temporal MODIS Images. Remote Sensing of Environment, Vol. 95(4), 480-492.

Xiao, X., Boles, S., Frolking, S., Li, C., Babu, J. Y., Salas, W. and Moore III, B., 2006, Mapping Paddy Rice Agriculture in South and Southeast Asia Using Multi-Temporal MODIS Images. Remote Sensing of Environment, Vol. 100(1), 95113. 